\title{
Network Size or Proximity? Association of Network Characteristics with Violence-Related Stress and PTSD Among Racial/Ethnic Minorities in Chicago
}

J Gen Intern Med 37(1):255-7

DOI: $10.1007 / \mathrm{s} 11606-021-06607-\mathrm{w}$

(c) Society of General Internal Medicine 2021

\section{BACKGROUND}

The growing epidemic of violence in urban cities has been linked to stress-related health disorders and PTSD. ${ }^{1}$ Social networks, broadly defined as an individual's personal and professional relationships, may be protective against these consequences. ${ }^{2}$ However, studies on network size have been mixed. ${ }^{2}$ We hypothesized that network proximity, the physical closeness of network confidants, may help explain differences in the level of protection conferred by social networks. In this study, we compared network size alone versus network size and proximity, to examine associations between these characteristics and psychosocial health (violence-related stress and PTSD) in a high-risk population.

\section{METHODS}

A sample of 504 adults were surveyed from two South and West side Chicago clinics in 2018. We limited analysis to 297 participants who self-reported lifetime exposure to community violence as a direct victim, witness, close friend, or family member of someone who died violently, using items from the Brief Trauma questionnaire. $^{3}$ Network size and proximity were measured using survey items from the National Social Life Health and Aging Project. Participants were asked to list each network confidant ("Who are the people that you've most often discussed important things with over the past year?") and their time-based proximity ("How far in minutes or hours does [listed individual] live from you?"). Violence-related stress and PTSD were measured using validated items adapted from the Jackson

Received August 31, 2020

Accepted January 5, 2021

Published online January 27, 2021
Heart Study and Primary Care-PTSD Screen. Detailed study methods are described in prior work. ${ }^{4}$

We used logistic regression models to assess stress due to violence and PTSD as independent functions of network size and proximity, ${ }^{5}$ controlling for age, gender, race/ethnicity, education, insurance status, and clinic location.

\section{RESULTS}

Among the subset of participants reporting prior exposure to community violence $(n=297$; Table 1$)$, the majority were female $(69 \%)$ and non-Hispanic Black $(75 \%)$. Two-thirds were direct victims of robbery or assault $(66 \%)$; one-third $(31 \%)$ screened positive for PTSD. The median number of network confidants was 2. Larger network size alone was not associated with stress due to violence or PTSD (Table 2). However, having a larger network size ( $\geq 3$ confidants) within $30 \mathrm{~min}$ from home was significantly associated with $67 \%$ lower adjusted odds of PTSD (95\% CI, $0.12-$ 0.96), compared to those with no confidants within 30 minutes from home. Associations with stress due to violence were not statistically significant (Table 2).

\section{DISCUSSION}

In this sample of high-risk, racial/ethnic minority adults in Chicago, we found that network proximity, rather than network size alone, was associated with lower odds of PTSD. This study is among the first, to our knowledge, to compare network size and proximity, and their respective associations with the psychosocial consequences of violence. Our findings raise the possibility that close proximity to network confidants may be a key factor for mitigating the harmful effects of community violence. One possible reason is that physical proximity may facilitate a type of "extended kinship," providing reliable socioeconomic and emotional resources that are responsive to neighborhood events and conditions. ${ }^{6}$ 
Table 1 Participant Characteristics: Subgroup with Prior Exposure to Community Violence, Chicago, IL 2018

\begin{tabular}{|c|c|c|}
\hline $\begin{array}{l}\text { Participant } \\
N=\mathbf{2 9 7}\end{array}$ & No. & $\%$ \\
\hline \multicolumn{3}{|l|}{ Clinic } \\
\hline Academic Medical Center & 254 & 85.5 \\
\hline Federally-Qualified Health Center & 43 & 14.5 \\
\hline \multicolumn{3}{|l|}{ Age (years) } \\
\hline $18-34$ & 4 & 1.4 \\
\hline $35-49$ & 63 & 21.2 \\
\hline $50-64$ & 130 & 43.8 \\
\hline $65-79$ & 90 & 30.3 \\
\hline 80 and older & 10 & 3.4 \\
\hline \multicolumn{3}{|l|}{ Gender } \\
\hline Female & 205 & 69.0 \\
\hline Male & 92 & 31.0 \\
\hline \multicolumn{3}{|l|}{ Race } \\
\hline White non-Hispanic & 23 & 7.7 \\
\hline Black non-Hispanic & 224 & 75.4 \\
\hline Hispanic or Latino & 35 & 11.8 \\
\hline Other & 15 & 5.1 \\
\hline \multicolumn{3}{|l|}{ Primary language } \\
\hline English & 275 & 92.6 \\
\hline Spanish & 20 & 6.7 \\
\hline Other & 2 & 0.7 \\
\hline \multicolumn{3}{|l|}{ Educational attainment } \\
\hline Less than high school graduate & 50 & 16.8 \\
\hline High school graduate or GED equivalent ${ }^{\mathrm{a}}$ & 58 & 19.5 \\
\hline Some college or 2 -year degree & 105 & 35.4 \\
\hline 4-year college graduate or more & 77 & 25.9 \\
\hline Do not know or refused & 7 & 2.4 \\
\hline \multicolumn{3}{|l|}{ Insurance status } \\
\hline Private & 106 & 35.7 \\
\hline Medicaid or dual-eligible & 107 & 36.0 \\
\hline Medicare & 65 & 21.9 \\
\hline Other & 7 & 2.4 \\
\hline None & 9 & 3.0 \\
\hline Do not know or refused & 3 & 1.0 \\
\hline \multicolumn{3}{|l|}{ Type of exposure to community violence } \\
\hline Direct victim of robbery or assault & 196 & 66.0 \\
\hline Indirect witness, friend, or family member & 236 & 79.5 \\
\hline Stress due to violence at least some of the time & 215 & 72.4 \\
\hline Post-traumatic stress disorder (PTSD) ${ }^{\mathrm{b}}$ & 89 & 30.0 \\
\hline \multicolumn{3}{|l|}{ Network size } \\
\hline No confidants & 34 & 11.4 \\
\hline Small network (1-2 confidants) & 130 & 43.8 \\
\hline Large network ( $3+$ confidants $)$ & 130 & 43.8 \\
\hline & 3 & 1.0 \\
\hline \multicolumn{3}{|l|}{ Network size and proximity ${ }^{\mathrm{c}}$} \\
\hline No confidants within $30 \mathrm{~min}$ from home & 82 & 27.6 \\
\hline Small network within $30 \mathrm{~min}$ from home & 167 & 56.2 \\
\hline Large network within $30 \mathrm{~min}$ from home & 39 & 13.1 \\
\hline Missing & 9 & 3.0 \\
\hline
\end{tabular}

${ }^{a} G E D$ indicates General Educational Development certification. ${ }^{b} P T S D$ indicates a positive screen for post-traumatic stress disorder using the Primary Care PTSD Screen (PC-PTSD), developed by the US Department of Veterans Affairs' National Center for PTSD. 'Of the 1,030 travel times in our dataset, median travel time was 20 min with an interquartile range of $44 \mathrm{~min}$

Neither network size nor proximity was associated with reductions in violence-related stress. We theorize that while stress may be more pervasive in populations with chronic exposure to violence, PTSD, which is more closely associated with personal exposure to violence, may be more responsive to the benefits of local networks. For instance, individuals with PTSD may rely on close confidants to navigate daily activities and regulate hypervigilance symptoms.

This is a limited cross-sectional study that can support theory and measurement development. Currently, network proximity is not included in most validated tools to measure network characteristics. We were unable to account for whether participants knew each other due to survey anonymity; however, eligibility criteria and the large size of each site may have mitigated this concern. Moreover, network proximity was measured using self- 
Table 2 Association of Social Network Characteristics with Stress and Post-traumatic Stress Disorder in Adults Exposed to Community Violence

\begin{tabular}{|c|c|c|c|c|c|c|}
\hline \multirow[b]{2}{*}{ Social isolation characteristics } & \multicolumn{3}{|c|}{$\begin{array}{l}\text { Stress due to violence } \\
n=286\end{array}$} & \multicolumn{3}{|c|}{$\begin{array}{l}\text { Post-traumatic stress disorder } \\
n=277\end{array}$} \\
\hline & $\%$ & OR $(95 \%$ CI $)$ & $\begin{array}{l}\text { Adjusted OR } \\
(95 \% \mathrm{CI})^{\mathrm{a}}\end{array}$ & $\%$ & OR $(95 \% \mathrm{CI})$ & $\begin{array}{l}\text { Adjusted OR } \\
(95 \% \text { CI })^{\mathrm{a}}\end{array}$ \\
\hline \multicolumn{7}{|l|}{ Network size ${ }^{\mathrm{b}}$} \\
\hline No confidants & 81.8 & Ref & Ref & 35.5 & Ref & Ref \\
\hline $1-2$ confidants & 70.9 & $0.52(0.20-1.36)$ & $0.61(0.22-1.66)$ & 39.5 & $1.13(0.50-2.57)$ & $1.33(0.53-3.36)$ \\
\hline $3+$ confidants & 70.6 & $0.53(0.20-1.39)$ & $0.62(0.22-1.73)$ & 21.3 & $0.49(0.21-1.16)$ & $0.42(0.16-1.10)$ \\
\hline \multicolumn{7}{|l|}{ Network proximity $^{\mathrm{c}}$} \\
\hline No confidants within $30 \mathrm{~min}$ from home & 68.8 & Ref & Ref & 41.3 & Ref & Ref \\
\hline 1-2 confidants within $30 \mathrm{~min}$ from home & 70.4 & $0.83(0.46-1.52)$ & $0.91(0.48-1.71)$ & 29.6 & $0.66(0.37-1.16)$ & $0.69(0.37-1.28)$ \\
\hline $3+$ confidants within 30 min from home & 71.1 & $0.86(0.36-2.03)$ & $1.14(0.45-2.86)$ & 16.2 & $0.30(0.11-0.81)^{*}$ & $0.33(0.12-0.96)^{*}$ \\
\hline
\end{tabular}

${ }^{a}$ Logistic regression models were used to estimate differences between groups; adjusted for age, gender, racelethnicity, educational attainment, insurance type, and clinic location (academic medical center or federally-qualified health center). ${ }^{b}$ Based on the number of unique confidants, participants were asked to sequentially list confidants (i.e., "Looking back over the past year, who are the people that you most often discussed important things with?"), starting with the most important person. ${ }^{~}$ Network proximity was measured among participants who reported at least 1 network confidant; however, all survey participants reporting no confidants were included in the referent category. $* p<0.05$

reported rather than empiric travel time. Despite these limitations, this is one of the first studies to examine both network size and proximity in comparative analyses.

Network proximity may be an important consideration, in addition to network size, for future research. We found that network proximity was associated with lower odds of PTSD in a sample of racial/ethnic minority adults who reported traumatic exposure to community violence. In an era of growing social isolation despite enhanced digital connection, further study is needed on the role of local networks in mitigating the harmful health effects of violence.

Acknowledgements: Research reported in this publication was supported by the Agency for Healthcare Research and Buality (AHRQ) K12 grant in patient-centered outcomes research 5K12HS023007 (E.L. Tung, PI). E. Tung was also supported by the National Heart, Lung, and Blood Institute (NHLBI) of the National Institutes of Health 1K23HL145090-01 (E.L. Tung, PI). E. Tung and M. Peek were supported by the Chicago Center for Diabetes Translation Research P30DK092949, funded by the National Institute of Diabetes and Digestive and Kidney Diseases (NIDDK) of the National Institutes of Health.

Ololade Akingbade, $B S^{1}$

Monica E. Peek, MD, $\mathrm{MPH}^{2,3}$

Elizabeth L. Tung, $M D, M^{2,4}$

${ }^{1}$ Pritzker School of Medicine, University of Chicago, Chicago, IL, USA

${ }^{2}$ Section of General Internal Medicine, University of Chicago,

Chicago, IL, USA

${ }^{3}$ Chicago Center for Diabetes Translation Research, University of Chicago,

Chicago, IL, USA
${ }^{4}$ Center for Health and The Social Sciences, University of Chicago, Chicago, IL, USA

Corresponding Author: Ololade Akingbade, BS; Pritzker School of Medicine, University of Chicago, Chicago, IL, USA (e-mail: Ololade.Akingbade@uchospitals.edu).

\section{Compliance with Ethical Standards:}

This study was approved by the University of Chicago Institutional Review Board with written documentation of informed consent.

Conflict of Interest: The authors declare that they do not have a conflict of interest.

\section{REFERENCES}

1. Tung EL, Johnson TA, O'Neal Y, Steenes AM, Caraballo G, Peek ME. Experiences of community violence among adults with chronic conditions: Qualitative findings from Chicago. J Gen Intern Med. 2018;33(11):191320. https://doi.org/10.1007/s11606-018-4607-3.

2. Aartsen M, Veenstra M, Hansen T. Social pathways to health: On the mediating role of the social network in the relation between socio-economic position and health. SSM - Popul Heal. 2017;3(May):419-26. https://doi. org/10.1016/j.ssmph.2017.05.006.

3. Schnurr PP, Vieilhauer MJ, Weathers F, Findler M. The Brief Trauma Questionnaire. White River Junction, VT, National Center for PTSD, 1999.

4. Tung EL, Cagney KA, Hawkley LC, Peek ME. Social isolation, loneliness, and violence exposure in older adults. Health Affairs. 2019;38(10):167078. https://doi.org/10.1377/hlthaff.2019.00563.

5. Giles-Corti B, Vernez-Moudon A, Reis R, et al. City planning and population health: a global challenge. Lancet.2016;388:2912-24. https://doi.org/10.1016/S0140-6736(16)30066-6.

6. Hardaway CR, Sterrett-Hong E, Larkby CA, Cornelius MD. Family resources as protective factors for low-income youth exposed to community violence. J Youth Adolescence. 2016;45:1309-22. https://doi.org/10. 1007/s10964-015-0410-1.

Publisher's Note: Springer Nature remains neutral with regard to jurisdictional claims in published maps and institutional affiliations. 